\title{
DECOMPOSIÇÃO DE PRECURSORES METALORGÂNICOS: UMA TÉCNICA QUÍMICA DE OBTENÇÃO DE FILMES FINOS
}

Oswaldo Luiz Alves*, Célia Machado Ronconi

Instituto de Química, Universidade Estadual de Campinas, CP 6154, 13083-970 Campinas - SP

André Galembeck

Departamento de Química Fundamental/CCEN, Universidade Federal de Pernambuco, 50740-540 Recife - PE

Recebido em 6/7/00; aceito em 16/5/01

\begin{abstract}
METALLO-ORGANIC DECOMPOSITION: A CHEMICAL APPROACH TO THIN FILM DEPOSITION. This review focus the more relevant foundations and applications of the Metallo-Organic Decomposition (MOD) technique, mainly within the last decade. The technique has grown significantly, mainly due to the good results concerning the preparation of multicomponent oxide systems with composition, structural and morphologic control, in a relatively simple way. This opened new opportunities to obtain materials with well-defined electrical and optical properties.
\end{abstract}

Keywords: thin films; metallo-organic decomposition; MOD.

\section{INTRODUÇÃO}

O desenvolvimento de técnicas baseadas na fabricação de filmes finos, aplicada à ciência dos materiais é, sem dúvida, um dos grandes responsáveis pelo avanço tecnológico que experimentamos atualmente.

Filmes finos sólidos apresentam uma infinidade de aplicações tecnológicas dentre elas, citamos: dispositivos eletrocrômicos ${ }^{1,2}$, fotovoltáicos ${ }^{3,4}$, fotoluminescentes ${ }^{5}$, sensores ${ }^{6}$, baterias de estado sólido $^{7}$, células solares ${ }^{8}$, células a combustível ${ }^{9}$, gravadores e leitores magneto-ópticos ${ }^{10}$. As possibilidades de se estender, ainda mais, a gama de aplicações dos materiais, bem como a modulação das diversas propriedades são inúmeras.

O presente artigo tem como objetivo revisar os principais fundamentos e aplicações da técnica Decomposição de Precursores Metalorgânicos, $M O D$, na obtenção de filmes finos envolvendo sistemas multicomponentes, multicamadas e materiais dopados, principalmente nos últimos dez anos.

Os filmes são obtidos em temperaturas relativamente baixas, sendo que as condições experimentais não dependem de processamentos a vácuo ou etapas com formação de ge ${ }^{11}$. A presente revisão inclui aspectos relacionados com: i) preparação de filmes finos; ii) fundamentos básicos da $M O D$ e iii) correlação entre a $M O D$ e outras técnicas utilizadas na preparação de filmes finos inorgânicos. Com relação ao último ponto, procurou-se dar destaque às vantagens e desvantagens pertinentes a cada uma das técnicas que julgamos concorrentes. Finalmente, abordamos aspectos relacionados com as perspectivas da técnica $M O D$.

\section{FILMES FINOS}

O crescimento explosivo das tecnologias baseadas na preparação de filmes finos e membranas tem estimulado, consideravelmente, as pesquisas em química, física e biologia. Conseqüentemente, uma terminologia confusa emergiu na literatura científica, o que fez com que, em 1994, a International Union of Pure and Applied

\footnotetext{
* e-mail: oalves@iqm.unicamp.br
}

Chemistry - IUPAC publicasse uma série de recomendações relacionadas à preparação e caracterização de filmes finos sólidos, líquidos e membranas ${ }^{12}$. O leitor poderá consultar tal publicação para dirimir dúvidas relacionadas com a terminologia utilizada neste e em outros textos que tratam do assunto em questão.

Diversas são as técnicas descritas na preparação de filmes. A formação de um filme sólido por métodos aditivos envolve uma fonte de material que pode ser o próprio material a ser depositado ou um precursor que será posteriormente convertido no material de interesse depositado. A questão do transporte de massa está ligada especificamente à técnica de deposição envolvida, sendo que o substrato atuará, primordialmente, como suporte mecânico. As propriedades superficiais do suporte e suas interações com o material depositado são de fundamental importância neste processo. A escolha do substrato passa pelas seguintes considerações: i) tipo de superfície; ii) composição; iii) estabilidade química; iv) condutividade térmica; v) estabilidade térmica; vi) porosidade e vii) custo $^{12-14}$. Uma atenção maior deve ser voltada ao primeiro ponto, uma vez que a superfície do substrato formará a interface com o filme que terá um papel importante em sua adesão.

As técnicas de deposição de filmes finos podem ser divididas em três grupos principais: i) sputtering e deposição iônica assistida; ii) deposição de vapor físico $(P V D)$ ou químico $(C V D)$ e iii) crescimento de filme em fase líquida ${ }^{12}$. A técnica de Decomposição de Precursores Metalorgânicos está inserida nesta última categoria.

\section{DECOMPOSIÇÃO DE PRECURSORES METALORGÂNICOS (MOD)}

MOD é acrônimo de Metallo-Organic Decomposition. A técnica pode ser aplicada à preparação de materiais tanto na forma de sólido policristalino, quanto depositado na forma de filmes. O termo foi originalmente cunhado por Kuo, em 1974, em um artigo no qual propõe a técnica como uma alternativa a ser explorada pela indústria eletrônica ${ }^{15}$

São considerados como sendo metalorgânicos, compostos nos quais o íon metálico está ligado a um radical orgânico por meio de um heteroátomo.

As principais etapas da preparação de filmes pela $M O D$ podem ser resumidas como: i) escolha dos precursores; ii) escolha do solvente 
ou mistura de solventes; iii) preparação da solução para deposição, na qual os cátions metálicos devem estar na razão estequiométrica desejada; iv) deposição; v) evaporação do solvente; vi) pirólise e vii) cristalização. A espessura do filme pode ser controlada repetindo-se as etapas de deposição e pirólise.

O uso dos precursores em solução, implica que as distâncias de interdifusão necessárias para se atingir o equilíbrio são curtas, e podese chegar às fases de equilíbrio mais rapidamente, se comparado com outras técnicas. Tal situação implica em menor gasto de energia para a produção dos filmes. Além disso, permite a preparação de filmes com composição bastante homogênea e dopagem em nível de ppm ${ }^{11}$.

\section{PRECURSORES}

Os precursores adequados para a $M O D$ devem decompor diretamente sem evaporar, fundir ou deixar resíduos de carbono. É fundamental que apresentem alto teor de metal e alta solubilidade em solventes orgânicos, sendo que estes dois requisitos, antagônicos, devem ser ajustados para a melhor relação possível.

Outras características importantes como facilidade de obtenção e purificação, estabilidade e compatibilidade química entre os precursores e ainda, a geração de subprodutos de decomposição que não sejam tóxicos, entre outras, foram detalhadas em trabalho anterior ${ }^{11}$.

Os precursores mais empregados são carboxilatos, derivados do ácido 2-etilhexanóico ou do ácido neodecanóico. Alguns trabalhos na literatura apresentam como precursores apenas acetatos e alcóxidos ${ }^{16-19}$. Hu e col. prepararam filmes de $\mathrm{SrBi}_{2} \mathrm{Ta}_{2} \mathrm{O}_{9}$ utilizando como precursores butóxido de estrôncio, acetato de bismuto e etóxido de tântalo ${ }^{18}$. Neste caso, os precursores foram dissolvidos em ácido acético e pirimidina. Em outra preparação, Krupanidhi e Peng prepararam filmes de $\mathrm{BaTiO}_{3}$ e $\mathrm{SrTiO}_{3}$, utilizando como precursores o acetato de bário, acetato de estrôncio e butóxido de titânio ${ }^{16}$.

A utilização de precursores como alcóxidos e acetatos visa diminuir o teor de carbono para evitar a formação de filmes porosos. Por outro lado, a manipulação de alcóxidos deve ser realizada, muitas vezes, em atmosfera inerte, ou controlando-se o teor de umidade do ambiente, de modo a evitar que os precursores sofram hidrólise, que pode levar à segregação de fases no material obtido.

Portanto, a escolha dos precursores deve ter um compromisso com a qualidade e a reprodutibilidade dos filmes, quer seja em relação à morfologia e estrutura, quer seja em relação às suas propriedades.

Alguns novos precursores metalorgânicos têm sido sintetizados no Laboratório de Química de Estado Sólido (LQES), do Instituto de Química da Unicamp, com base nos procedimentos propostos por Vest e Singaram ${ }^{20}$, e de acordo com informações técnicas fornecidas pela Strem Chemicals (USA). Os precursores sintetizados foram o tri-etóxido-di-(2-etil-hexanoato) de nióbio (V) e o 2-etilhexanoato de antimônio (III). Os precursores em questão foram adequadamente caracterizados, tanto no que diz respeito à sua composição e estrutura, como quanto à sua decomposição térmica.

\section{DEPOSIÇÃo}

O ponto de partida para a formação de filmes finos, por $M O D$, é a obtenção da solução precursora. A deposição dos filmes pode ser realizada por meio de técnicas de deposição de filmes em fase líquida, como efetuado para o processo sol-gel ${ }^{20}$. Dip-coating, spincoating e spray pyrolysis são as mais utilizadas ${ }^{14,21}$.

É importante que a deposição e a evaporação do solvente se dêem de forma que não ocorra a segregação dos precursores, e que a deposição permita controlar simultaneamente a uniformidade e espessura dos filmes, as quais terão conseqüências diretas sobre as propriedades dos materiais processados ${ }^{11}$.
Comparativamente às outras técnicas de deposição de filmes como $C V D$, sputtering e molecular beam epitaxy, as técnicas de spin coating e dip coating exigem menos investimento em termos de equipamentos, pelo fato de não ser necessário utilizar técnicas de vácuo acopladas à deposição.

\section{DECOMPOSIÇÃO TÉRMICA DOS PRECURSORES}

A microestrutura do material é desenvolvida durante a etapa de pirólise, portanto, deve-se ter acesso às faixas de temperatura nas quais ocorrem evaporação do solvente, pirólise dos precursores e avaliar sua volatilidade, além de verificar a influência da velocidade de aquecimento no processo de decomposição térmica.

Uma velocidade de aquecimento muito rápida pode levar a perdas do precursor por volatilização, enquanto um aquecimento excessivamente lento leva, muitas vezes, à eliminação incompleta da parte orgânica do precursor. A técnica de análise termogravimétrica (TGA) auxilia na obtenção dos parâmetros de tratamento térmico dos filmes como, por exemplo, taxa de aquecimento, temperatura de pirólise e temperatura de cristalização.

$\mathrm{Na}$ obtenção do $\mathrm{BiVO}_{4}$ policristalino, pelo LQES, os precursores empregados foram o 2-etil-hexanoato de bismuto $\mathrm{Bi}(\text { hex })_{3}$ e o oxi-acetilacetonato de vanádio (IV) $\left(\mathrm{VO}(\mathrm{acac})_{2}\right)$, dissolvidos em acetilacetona $^{22}$. A decomposição do precursor de bismuto ocorre em uma faixa ampla de temperatura, em contraste com o caso do precursor de vanádio, o qual apresentou dois eventos distintos de perda de massa, ambos ocorrendo em uma faixa estreita de temperatura. De modo geral, é preferível que a decomposição térmica dos precursores seja processada numa faixa estreita de temperatura, característica de processos regidos por uma cinética rápida.

O estudo do comportamento térmico deve ser realizado para cada um dos precursores de maneira isolada e também da mistura em solução, de modo que sejam identificadas não apenas a temperatura em que o processo de decomposição se completa, mas também se o comportamento térmico dos precursores é alterado pela presença do solvente ou se ocorre volatilização de algum dos precursores, que poderia levar à obtenção de fases com estequiometria diferente da desejada.

Preferencialmente, o processo de decomposição deve-se completar em temperaturas próximas para os diferentes precursores. No caso da obtenção do $\mathrm{BiVO}_{4}$ verificou-se que a decomposição dos dois precursores completou-se em aproximadamente $380{ }^{\circ} \mathrm{C}$. Entretanto, após a evaporação do solvente, o comportamento térmico da mistura foi diferente do observado individualmente para os precursores, sendo que o processo final ocorreu por volta de $500{ }^{\circ} \mathrm{C}^{22}$.

Na Figura 1, são mostradas as curvas termogravimétricas do 2etil-hexanoato de cobre (II) e de uma solução em xileno deste precursor, utilizada na deposição de filmes de $\mathrm{CuO}^{23}$. A decomposição do precursor puro (Fig. 1(A)) ocorre em etapa única, em estreita faixa de temperatura. No caso da solução (Fig. 1(B)), observa-se a presença de dois eventos distintos, sendo que o segundo deles é perfeitamente superponível com a decomposição do $\mathrm{Cu}(\mathrm{hex})_{2}$. A perda de massa, observada até aproximadamente $125^{\circ} \mathrm{C}$, está relacionada com a evaporação do solvente. Verifica-se que a presença do solvente não altera o comportamento térmico do precursor, configurando situação ideal para a obtenção de filmes finos.

Os produtos da decomposição dos precursores podem ser identificados, pelo uso da técnica de espectrometria de massas (EM). Na Figura 2, são apresentados os resultados para o $\mathrm{Sn}(\text { hex })_{2}$, obtidos pelo acoplamento da análise termogravimétrica com a espectrometria de massas (TGA-EM).

$\mathrm{Na}$ Tabela 1, estão listadas as atribuições tentativas para as massas observadas durante a decomposição ${ }^{24}$. 


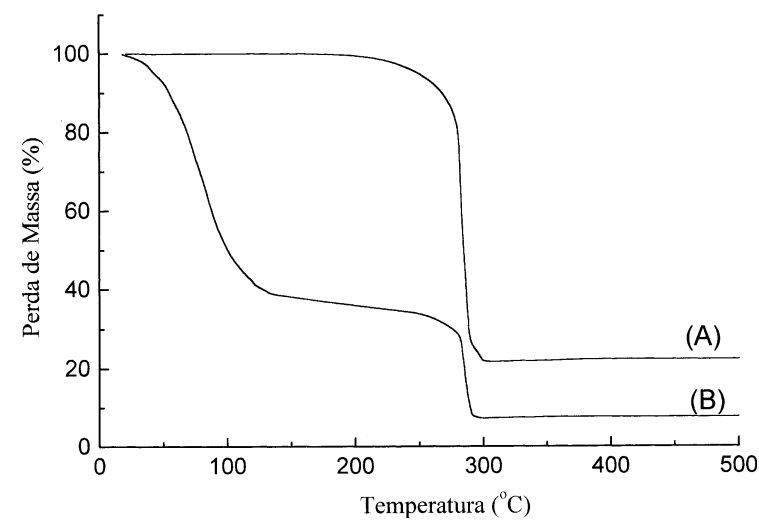

Figura 1. Curvas termogravimétricas: (A) $\mathrm{Cu}(\text { hex })_{2} ;(B)$ solução de $\mathrm{Cu}(\text { hex })_{2}$ em xileno. (Taxa de aquecimento de $10^{\circ} \mathrm{C} \mathrm{m^{-1 }}$, fluxo de ar sintético $\left.\left(50 \mathrm{~cm}^{3} \mathrm{~min}^{-1}\right)\right)$.

B

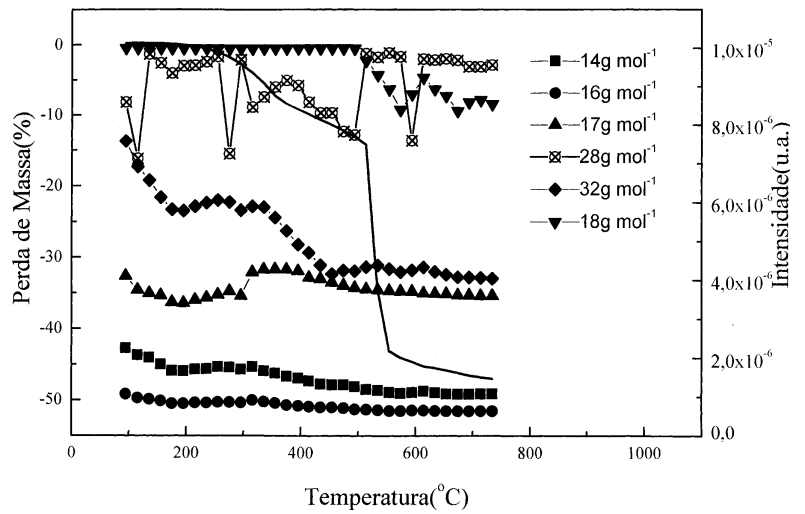

B

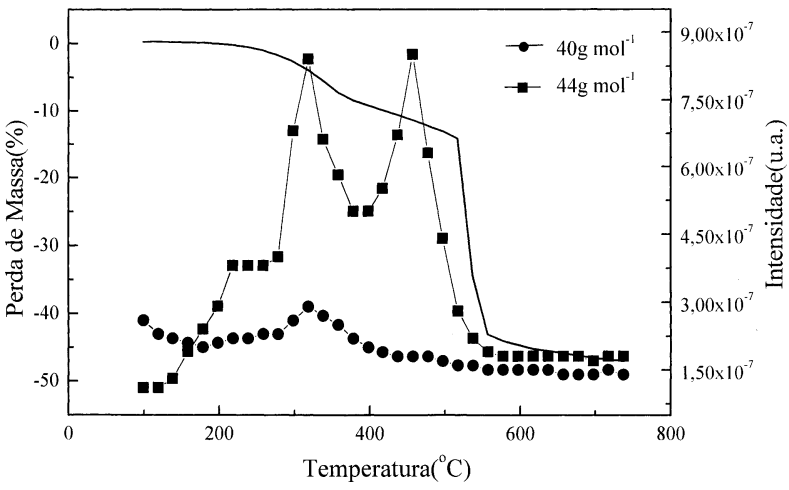

Figura 2. Curva termogravimétrica e produtos da decomposição do $\operatorname{Sn}\left(\right.$ hex) ${ }_{2}$.

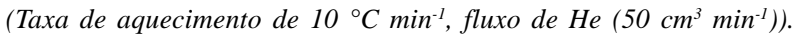

Tabela 1. Atribuições tentativas para as massas molares observadas durante a decomposição do $\operatorname{Sn}(\text { hex })_{2}$.

\begin{tabular}{cc}
\hline Massa/g mol ${ }^{-1}$ & Atribuição Tentativa \\
\hline 14 & $\mathrm{~N} \mathrm{ou} \mathrm{CH}_{2}$ \\
16 & $\mathrm{O} \mathrm{ou} \mathrm{CH}_{4}$ \\
17 & $\mathrm{HO}$ \\
18 & $\mathrm{H}_{2} \mathrm{O}$ \\
28 & $\mathrm{~N}_{2}, \mathrm{C}_{2} \mathrm{H}_{4}$ ou CO \\
32 & $\mathrm{O}_{2} \mathrm{ou} \mathrm{CH}_{3} \mathrm{OH}$ \\
40 & $\mathrm{C}_{2} \mathrm{O} \mathrm{ou} \mathrm{C}_{3} \mathrm{H}_{4}$ \\
44 & $\mathrm{CO}_{2}, \mathrm{CH}_{3} \mathrm{COH} \mathrm{ou}_{3} \mathrm{H}_{8}$ \\
\hline
\end{tabular}

Cabe ressaltar que estas análises foram realizadas sob fluxo de hélio, portanto, a atmosfera não reage com os produtos que estão sendo liberados.

Outro fato importante é que a medida foi realizada sob fluxo de nitrogênio na etapa TGA. Possivelmente, a massa de $14 \mathrm{~g} \mathrm{~mol}^{-1} \mathrm{ob}-$ servada possa ser atribuída à presença de nitrogênio. $\mathrm{O}$ valor de $28 \mathrm{~g}$ mol $^{-1}$ pode estar associado à liberação de $\mathrm{CO}$, uma vez que verificase uma oscilação de intensidade com o aumento de temperatura.

\section{CONTROLE DAS CARACTERÍSTICAS/PROPRIEDADES PELAS VARIÁVEIS DE PROCESSO}

O controle da espessura dos filmes está associado, essencialmente, ao método de deposição empregado. No caso da deposição por dipcoating, a velocidade com que o substrato é retirado da solução é um dos fatores determinantes. Filmes obtidos por spinning têm a espessura controlada pela velocidade e tempo de rotação do substrato. Em ambos, a concentração do precursor e o número de deposições são importantes ${ }^{14,25}$.

A formação de filmes porosos ou densos pode ter origem na etapa de eliminação do solvente, estando associada principalmente às interações entre o precursor e o solvente, entre o solvente e o substrato, à taxa de aquecimento e à temperatura de evaporação do solvente.

O tamanho dos cristalitos pode também ser modulado. De modo geral, o tempo e a temperatura dos tratamentos térmicos empregados na etapa de cristalização determinam as características principais relacionadas à morfologia. Exemplo do efeito do tratamento térmico sobre a morfologia foi verificado para filmes de $\mathrm{LiNbO}_{3}{ }^{26}$. Os autores usaram dois tipos de tratamentos: i) pirólise térmica rápida, em atmosfera de ar e ii) pirólise lenta. Os filmes obtidos por aquecimento rápido apresentaram planos quadrados e densos, enquanto naqueles sob aquecimento lento, tais planos mostraram-se espaçados. A cristalinidade também sofreu influência: o tratamento térmico rápido formou filmes com a estrutura perovskita a $530{ }^{\circ} \mathrm{C}$, e com o tratamento lento, os filmes cristalizaram-se a $580{ }^{\circ} \mathrm{C}$. O efeito do tratamento térmico também influenciou as propriedades elétricas dos filmes de $\mathrm{LiNbO}_{3}$, ou seja, o aquecimento rápido forneceu filmes com resistência elétrica menor do que aqueles obtidos por aquecimento lento.

Ainda em relação à formação de filmes de $\mathrm{LiNbO}_{3}$, Braunstein e col. ${ }^{27}$ observaram que, aquecendo-se lentamente os filmes a $500{ }^{\circ} \mathrm{C} / 10 \mathrm{~min}$, para promover a pirólise e, em seguida, entre $500{ }^{\circ} \mathrm{C} \mathrm{e}$ $1000^{\circ} \mathrm{C} / 1 \mathrm{~h}$, para dar lugar à cristalização, os filmes não apresentavam morfologia contínua em toda sua extensão. Por outro lado, quando os filmes foram aquecidos diretamente a $550{ }^{\circ} \mathrm{C}$, para induzir uma decomposição rápida dos precursores e, subseqüentemente a $900{ }^{\circ} \mathrm{C} / 3 \mathrm{~h}$, formaram-se filmes contínuos e densos. O aquecimento lento dos filmes, após a etapa de evaporação do solvente, diminuiu gradativamente a viscosidade dos precursores até se tornar suficientemente pequena a tal ponto que os efeitos de tensão superficial passaram a ser predominantes e induziram a formação de gotas $^{28}$. Tal fato foi o responsável pela formação de filmes descontínuos, quando utilizado aquecimento lento.

A evolução da morfologia está diretamente relacionada à cinética do processo de decomposição térmica. No caso dos filmes de $\mathrm{LiNbO}_{3}$, o aquecimento rápido reduziu o tempo de contato das forças interfaciais, evitando que os precursores formassem gotas pequenas sobre o substrato.

A morfologia dos filmes preparados pela $M O D$ depende, também, do tipo de composto final. A experiência do LQES na preparação de diferentes tipos de filmes pela técnica de dip coating, por exemplo, $\beta-\mathrm{Bi}_{2} \mathrm{O}_{3}, \mathrm{CuO}, \mathrm{CeO}_{2}$ e $\mathrm{Cd}_{2} \mathrm{SnO}_{4}$ mostrou que os mesmos podem apresentar morfologias bastante distintas, como apresentado na Figura 3. 

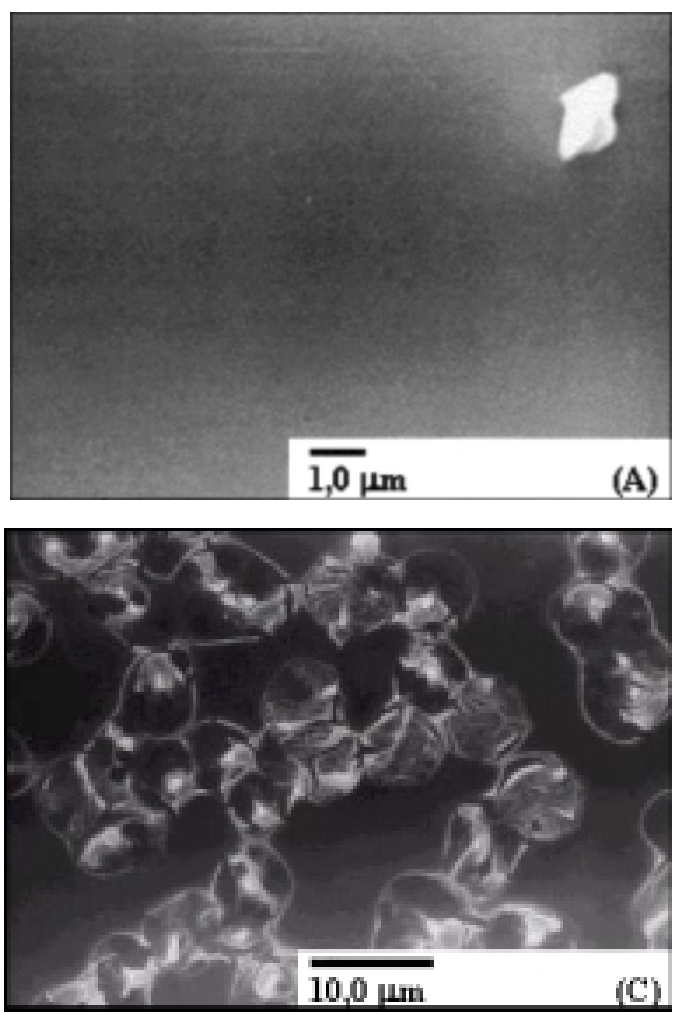
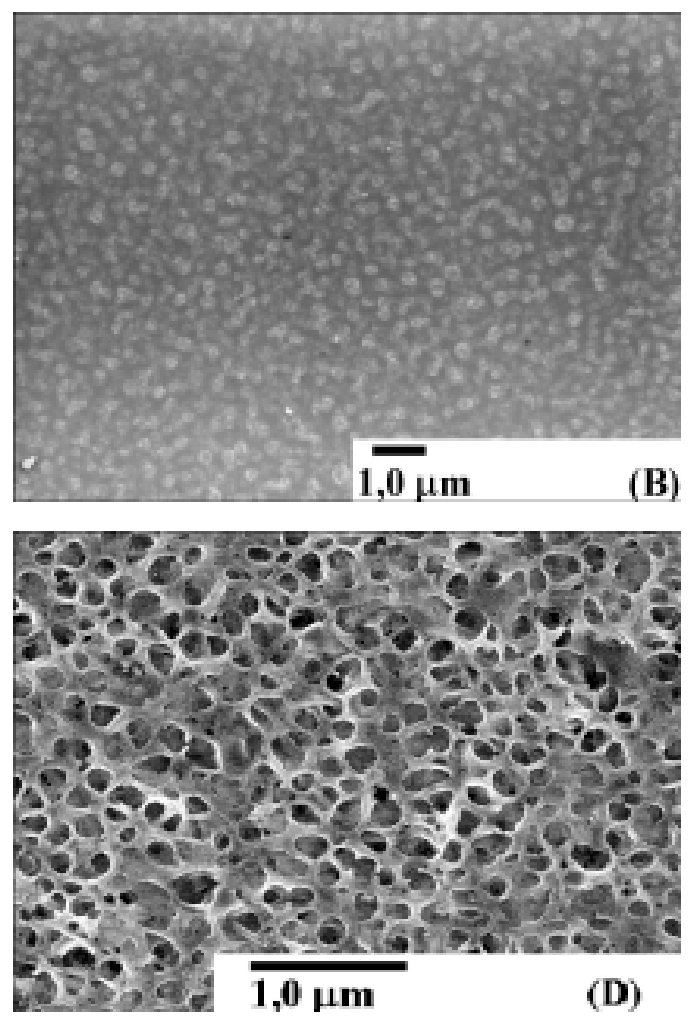

Figura 3. Morfologia de filmes preparados por MOD. (A) $\mathrm{B}_{-} \mathrm{Bi}_{2} \mathrm{O}_{3}$; (B) $\mathrm{CuO}$; (C) $\mathrm{CeO}_{2}$ e (D) $\mathrm{Cd}_{2} \mathrm{SnO}_{4}$.

No caso dos filmes de $\beta-\mathrm{Bi}_{2} \mathrm{O}_{3}$, foram obtidas amostras nas quais não foi possível distinguir os contornos dos grãos, até o limite de resolução da técnica de microscopia eletrônica de verredura utilizada (aumento de 30000 vezes). Na Figura 3(A), a partícula clara, no canto superior direito, é uma impureza, apresentada para efeito de contraste. A morfologia só pôde ser elucidada por microscopia de força atômica (AFM), mostrando a presença de partículas com diâmetro médio de aproximadamente $75 \mathrm{~nm}$ e rugosidade inferior a $9 \mathrm{~nm}$. Possivelmente, a alta concentração da solução precursora e a forte interação entre o óxido de bismuto com o $\mathrm{SiO}_{2}$ do substrato foram as responsáveis pela homogeneidade do filme. Adicionalmente, a baixa velocidade com que o substrato foi retirado da solução $(0,5 \mathrm{~cm} / \mathrm{min})$, fez com que as camadas depositadas fossem suficientemente finas, de modo a permitir a liberação do solvente sem que ocorresse a formação de poros.

Na Fig. 3(B), é mostrada a morfologia de um filme de CuO. A imagem foi obtida por retroespalhamento (BEI) e seu baixo contraste é característico de amostras que apresentam baixa rugosidade. As regiões mais claras correspondem a saliências na superfície do filme ${ }^{29}$.

No caso do óxido de cério, tem-se uma situação em que não foram obtidos filmes contínuos, contudo, observou-se a formação de "ilhas" de $\mathrm{CeO}_{2}$ interconectadas (Figura 3C). Verificou-se que este padrão originou-se na etapa de evaporação do solvente, mantendose após a pirólise e a cristalização. No caso deste óxido, foi possível alterar, de modo controlado, o diâmetro das partículas e sua rugosidade, variando-se os parâmetros de obtenção dos filmes utilizando um planejamento fatorial ${ }^{29,30}$.

Os filmes de $\mathrm{Cd}_{2} \mathrm{SnO}_{4}$ apresentaram uma superfície porosa, Figura $3 \mathrm{D}^{31}$. Para este material a formação da morfologia porosa está diretamente relacionada com o tipo de solvente utilizado, no caso o xileno. Verificou-se que a morfologia porosa origina-se na etapa de evaporação do xileno.

Os filmes de $\mathrm{BiVO}_{4}$ apresentaram-se porosos, fato atribuído à solução precursora de bismuto e vanádio, que contém baixa concentração dos precursores, impossibilitando o recobrimento total da superfície do substrato em cada uma das deposições. $\mathrm{O}$ aumento do número de camadas levou à formação de um filme com recobrimento mais uniforme, tendo sido observadas partículas com dimensões variando entre 0,12 e $0,24 \mu \mathrm{m}^{22}$. Os filmes de $\mathrm{BiVO}_{4}+\mathrm{VO}_{2}$, obtidos por $C V D$, apresentaram morfologia bastante rugosa $(0,6 \mathrm{~mm}$, em média), com tamanho de grãos variando entre 0,06 e $0,50 \mathrm{~mm}^{32}$.

\section{MOD $e$ CVD (DEPOSIÇÃO QUÍMICA DE VAPOR)}

Faremos, aqui, alguns comentários sobre as técnicas $M O D$ e $C V D$. Primeiramente, não foram encontrados na literatura artigos descrevendo a obtenção de um material por $C V D$ e $M O D$, respectivamente, por um mesmo grupo de pesquisa.

As técnicas baseadas em $C V D$, sem dúvida, alcançaram grande sucesso devido ao êxito de sua aplicação na obtenção de filmes semicondutores, constituindo-se atualmente na mais importante técnica utilizada na indústria de microeletrônica. Além disso, o desenvolvimento de novos tipos de precursores e a modelagem computacional contribuíram decisivamente para este crescimento $^{33,34}$.

Todavia, no caso da obtenção de sistemas óxidos contendo mais de um metal, a $C V D$ mostra-se sensível às diferenças de volatilidade dos diferentes precursores, o que dificulta a obtenção de materiais constituídos de uma única fase. Esta limitação, em princípio, não existe em $M O D$, uma vez que os precursores não são voláteis e são pirolisados somente após as etapas de deposição e de evaporação do solvente. Contudo, não é reportada na literatura a aplicação de $M O D$ na preparação de sistemas não-óxidos como, por exemplo, os semicondutores do tipo III-V. Nesta área a MOCVD (Deposição de Vapor Químico de Precursores Organometálicos) mostra-se uma "technique de choix".

A aplicação da $M O D$ permitiu a preparação de filmes finos de 
$\mathrm{BiVO}_{4}$, a partir de oxi-acetilacetonato de vanádio $\left(\mathrm{VO}(\mathrm{acac})_{2}\right)$ e 2-etilhexanoato de bismuto $\mathrm{Bi}(\text { hex })_{3}$, constituindo uma fase única, pela primeira vez descrita na literatura ${ }^{22}$.

A obtenção, por $C V D$, de filmes de óxidos de bismuto e vanádio a partir de oxi-acetilacetonato de vanádio e trifenil-bismuto levou, dependendo das condições de preparação, à formação de misturas de fases contendo $\mathrm{BiVO}_{4} \mathrm{eVO}_{2}$. Sob condições bem definidas, Barreca e col. conseguiram obter uma fase mais rica em $\mathrm{Bi}$ e $\mathrm{V}$, do tipo $\mathrm{Bi}_{4} \mathrm{~V}_{2} \mathrm{O}_{11}{ }^{32}$.

\section{$M O D$ e SOL-GEL}

O processo sol-gel e a decomposição de precursores metalorgânicos $(M O D)$ podem ser comparados do ponto de vista da reatividade química ${ }^{35}$.

Quando no processo sol-gel diferentes precursores metálicos são combinados e a hidrólise é cuidadosamente controlada, a etapa de condensação leva à formação de uma rede mista metal-oxigêniometal. Este material normalmente é não-cristalino e, sob tratamento térmico, dá origem a um óxido. A etapa de hidrólise é a mais complexa, e depende de fatores como: i) tipo de metal e suas propriedades (eletronegatividade, carga e número de coordenação); ii) pH do meio de hidrólise; iii) natureza do ligante; iv) temperatura de hidrólise e v) razão água/metal ${ }^{25}$.

Em $M O D$, a formação dos óxidos ocorre de maneira mais direta ${ }^{35}$ :

$\mathrm{M}-\mathrm{O}-\mathrm{L} \rightarrow \mathrm{MO}$ ou $\mathrm{MCO}_{3}+$ produtos de pirólise

$\mathrm{M}^{\prime} \mathrm{O}+\mathrm{M}^{\prime \prime} \mathrm{CO}_{3} \rightarrow \mathrm{M}^{\prime} \mathrm{M}^{\prime} \mathrm{O}_{\mathrm{x}}+\mathrm{CO}_{2}$

$\mathrm{M}-\mathrm{O}-\mathrm{L}+\mathrm{M}$ '-O-L $\rightarrow \mathrm{MM}^{\prime} \mathrm{O}_{\mathrm{x}}+$ produtos de pirólise

Os produtos da decomposição dependem da natureza do cátion e não do ligante, com a condição de que este contenha apenas $\mathrm{C}, \mathrm{H} \mathrm{e}$ O. Como a decomposição térmica é a "força dirigente" do processo, os precursores devem satisfazer certas condições, como mencionadas anteriormente, contrastando, portanto, com os precursores sol-gel.

No caso do processo sol-gel, os precursores utilizados na grande maioria dos casos são alcóxidos metálicos. Tais alcóxidos são sujeitos a um ataque nucleofílico pela água. A velocidade de hidrólise deve ser controlada pela quantidade de água adicionada e/ou pela ação de um catalisador. É necessário, ainda, que o produto derivado da hidrólise tenha um ponto de ebulição relativamente baixo, para que possa ser removido do gel por meio de aquecimento moderado. Outra condição: os alcóxidos devem ser solúveis em um álcool com o mesmo número de átomos de carbono dos ligantes alcóxidos, ou em um solvente compatível.

Por outro lado, na $M O D$, os precursores mais utilizados são metais ligados a grupos orgânicos, normalmente carboxilatos metálicos e alcóxidos modificados ${ }^{11}$. Tais ligantes são decompostos por termólise. Assim, não é adequado que os precursores sublimem e/ou evaporem. A solubilidade é essencial para que a mistura se dê no nível molecular. Para ajustar-se a reologia dos precursores, na $M O D$, é fundamental que estes sejam solúveis em solventes orgânicos.

Em relação ao processamento, a hidrólise dos alcóxidos metálicos, no processo sol-gel, leva a hidróxidos ou óxidos hidratados. As propriedades ácido-base das espécies hidrolíticas dependem da eletronegatividade do cátion. $\mathrm{Na} M O D$, a decomposição térmica dos carboxilatos metálicos pode levar à formação de carbonatos metálicos, cuja estabilidade é determinada pela eletropositividade do cátion: quanto mais eletropositivo é o metal, mais estável é o carbonato. Os metais alcalinos, alcalinos terrosos e lantanídeos formam carbonatos estáveis, que se decompõem em temperaturas elevadas $\left(>600^{\circ} \mathrm{C}\right)$. Por outro lado, os carbonatos metálicos de metais de transição decom- põem-se rapidamente em óxidos metálicos e $\mathrm{CO}_{2}$. A formação dos carbonatos independe da natureza do ligante, sendo determinada pela estabilidade termodinâmica do óxido, na presença de $\mathrm{CO}_{2}$. Os carboxilatos de metais nobres, diferentemente, decompõem-se levando o elemento à sua forma metálica ${ }^{35}$.

Em relação aos produtos, a força que direciona a formação de sistemas de óxidos mistos, pelo processo sol-gel, deve ser analisada em termos das reações ácido-base. $\mathrm{Na} M O D$, a formação de óxidos mistos é proveniente da reação sólido-sólido entre óxidos e/ou carbonatos produzidos durante o tratamento térmico, ou, ainda, da formação direta do óxido misto.

Muitas cerâmicas de óxidos mistos contêm um cátion altamente eletropositivo. Quando sua preparação é feita pelo processo sol-gel são formados hidróxidos estáveis distintos como produtos intermediários, enquanto que, na $M O D$, formam-se carbonatos. Na Tabela 2, são mostrados alguns óxidos metálicos mistos e os intermediários que precederam sua formação, por sol-gel ou por $M O D$.

Tabela 2. Produtos da decomposição térmica por $M O D$ e da hidrólise pelo processo sol-gel.

\begin{tabular}{lcc}
\hline Material & Sol-Gel & $M O D$ \\
\hline $\mathrm{LiNbO}_{3}$ & $\mathrm{LiOH}+\mathrm{HNbO}_{3}$ & $\mathrm{Li}_{2} \mathrm{CO}_{3}+\mathrm{Nb}_{2} \mathrm{O}_{5}$ \\
$\mathrm{BaTiO}_{3}$ & $\mathrm{Ba}(\mathrm{OH})_{2}+\mathrm{TiO}_{2}$ & $\mathrm{BaCO}_{3}+\mathrm{TiO}_{2}$ \\
$\mathrm{BaB}_{2} \mathrm{O}_{4}$ & $\mathrm{Ba}(\mathrm{OH})_{2}+2 \mathrm{~B}(\mathrm{OH})_{3}$ & $\mathrm{BaCO}_{3}+\mathrm{B}_{2} \mathrm{O}_{3}$ \\
\hline
\end{tabular}

Por conseguinte, pode-se concluir que tanto a hidrólise no processo sol-gel, como a decomposição de precursores metalorgânicos, levam à formação de intermediários diferentes, que dependem da sua posição no sistema periódico.

Outra diferença marcante entre o processo sol-gel e a $M O D$ relaciona-se com as energias de reação. Na Tabela 3, são listados alguns valores de entalpia de reação para o processo sol-gel e para a decomposição de precursores metalorgânicos ${ }^{35}$.

Tabela 3. Comparação entre as entalpias de reação para alguns sistemas obtidos pelo processo sol-gel e pela $M O D$.

\begin{tabular}{ll}
\hline $\mathrm{BaCO}_{3}+\mathrm{TiO}_{2} \rightarrow \mathrm{BaTiO}_{3}+\mathrm{CO}_{2}$ & $\Delta \mathrm{H}=101 \mathrm{~kJ}(M O D)$ \\
$\mathrm{BaCO}_{3}+\mathrm{B}_{2} \mathrm{O}_{3} \rightarrow \mathrm{BaB}_{2} \mathrm{O}_{4}+\mathrm{CO}_{2}$ & $\Delta \mathrm{H}=108,8 \mathrm{~kJ}(M O D)$ \\
$\mathrm{Ba}(\mathrm{OH})_{2}+\mathrm{TiO}_{2} \rightarrow \mathrm{BaTiO}_{3}+\mathrm{H}_{2} \mathrm{O}$ & $\Delta \mathrm{H}=-20,9 \mathrm{~kJ}$ (sol-gel) \\
$\mathrm{Ba}(\mathrm{OH})+2 \mathrm{~B}\left(\mathrm{OH}_{4}^{-}\right) \mathrm{H}^{+} \rightarrow \mathrm{BaB}_{2} \mathrm{O}_{4}+6 \mathrm{H}_{2} \mathrm{O}$ & $\Delta \mathrm{H}=-2426,7 \mathrm{~kJ}$ (sol-gel) \\
\hline
\end{tabular}

Na $M O D$, a entalpia de reação, para os exemplos citados, é endotérmica. Possivelmente, a reação na $M O D$ é feita aumentandose a temperatura até o ponto em que a contribuição da entropia $(\Delta S)$ é suficientemente elevada para sobrepor a entalpia $(\Delta \mathrm{H})$ positiva da reação e tornar a energia livre $(\Delta \mathrm{G})$ negativa: $\Delta \mathrm{G}=\Delta \mathrm{H}-\mathrm{T} . \Delta \mathrm{S}$. Para o processo sol-gel, a reação é exotérmica e espontânea.

A principal vantagem do processo $M O D$ em relação ao sol-gel é que os precursores não são sensíveis às condições ambientes, principalmente umidade. Por outro lado, uma desvantagem do processo $M O D$ é que, devido ao grande teor de carbono, ocorre significativa contração de volume durante as etapas de secagem e pirólise. Como consequiência, os filmes formados podem apresentar poros e trincas. Tal problema pode ser, em princípio, contornado reduzindo-se a quantidade de carbono no precursor, ou preparando-se soluções mais concentradas, ou, ainda, alterando-se outras variáveis como taxa de aquecimento, temperatura de pirólise, solvente, etc. Nesta etapa, um planejamento fatorial torna-se ferramenta essencial para auxiliar na obtenção de filmes de boa qualidade. 
No caso do sol-gel, é de fundamental importância a obtenção de um retículo não-cristalino, resultante da hidrólise e condensação dos precursores: o gel. Em sistemas multicomponentes, as distintas velocidades de hidrólise dos diferentes precursores podem originar compostos não-homogêneos, de forma que a fase de interesse não seja obtida. Tais compostos poderão ser processados posteriormente, de modo a se obter materiais como vidros, cerâmicas em forma de monolitos, xerogéis, entre outros.

A técnica de $M O D$ dificilmente permitirá a obtenção de materiais não-cristalinos, uma vez que, em se partindo de uma solução verdadeira, as distâncias de difusão são muito pequenas, e o sistema rapidamente tende a atingir o equilíbrio termodinâmico, a partir do momento em que os radicais orgânicos foram volatilizados/ pirolisados.

Cabe ressaltar ser a escolha do método de preparação a etapa primordial do trabalho. Não só os recursos disponíveis devem ser considerados, mas também, a aplicação que se deseja dar ao material, uma vez que cada método de preparação fornece filmes com morfologias e estruturas bem definidas e que irão influenciar nas suas propriedades elétricas, ópticas, etc.

Há na literatura trabalhos nos quais os autores prepararam filmes finos ferroelétricos pelo processo $M O D$ e sol-gel, traçando algumas comparações entre os métodos. Tais filmes foram analisados com relação à cristalização, morfologia e propriedades.

Os filmes de $\mathrm{SrBi}_{2} \mathrm{Ta}_{2} \mathrm{O}_{9}, \mathrm{SrBi}_{2} \mathrm{NbTaO}_{9}$ e $\mathrm{SrTiO}_{3}$ preparados por ambas as técnicas, mostraram a formação de uma fase única, com orientação aleatória; já aqueles preparados por $M O D$, apresentaramse mais porosos ${ }^{36}$.

Hayashi e col. também obtiveram filmes de $\mathrm{SrBi}_{2} \mathrm{Ta}_{2} \mathrm{O}_{9}$, por $M O D$ e sol-gel, sendo que as propriedades dielétricas obtidas pela utilização da técnica de $M O D$ foram significativamente melhores. $\mathrm{O}$ fato foi atribuído ao tipo de orientação gerado nos filmes preparados por sol-gel, que não contribuiu para a polarização espontânea do sistema. Tal orientação derivou da natureza da coordenação dos alcóxidos em solução, fenômeno este ausente na $M O D^{37}$.

Adicionalmente, Klee e col. prepararam filmes de $\mathrm{Pb}\left(\mathrm{Zr}_{\mathrm{x}} \mathrm{Ti}_{1-\mathrm{x}}\right) \mathrm{O}_{3}$ (PZT) visando a comparação entre sol-gel e $M O D$. Na preparação de filmes PZT, pelo processo $M O D$, foram avaliados dois grupos de precursores: 2-etil-hexanoato de $\mathrm{Pb}(\mathrm{II})$, o tetra $n$-butilato de Ti e o acetilacetonato de $\mathrm{Zr}$ (IV) (precursores I). Os filmes formados pelo processo $M O D$ apresentaram grande contração de volume durante os processos de secagem do solvente e de pirólise. O segundo grupo de precursores foi selecionado considerando-se tal fato, portanto, com uma quantidade menor de carbono: acetato tri-hidratado de $\mathrm{Pb}$ (II), tetra $n$-butilato de Ti e tetra $n$-butilato de $\mathrm{Zr}$ (precursores II). Os precursores utilizados no processo sol-gel foram: acetato trihidratado de $\mathrm{Pb}$ (II), tetra-iso-propilato de Ti e tetra- $n$-butilato de $\mathrm{Zr}$ (precursores III) $^{38}$.

Os filmes sintetizados pelo processo $M O D$ (precursores I), com excesso de chumbo de $10 \%$ at., cristalizaram-se a $500^{\circ} \mathrm{C}$ com estrutura perovskita simples. Já aqueles obtidos a partir dos precursores II (processo $M O D$ ) e III (processo sol-gel) apresentaram-se multifásicos, cristalizando-se a $500^{\circ} \mathrm{C}$, porém com as fases perovskita e pirocloro. A fase perovskita pura foi obtida aquecendo-se os filmes entre $600^{\circ} \mathrm{e}$ $700^{\circ} \mathrm{C}$. A diferença na temperatura de formação da fase desejada (perovskita) foi atribuída ao excesso de chumbo, e não ao tipo de precursor.

A influência dos precursores foi observada na morfologia dos filmes. Aqueles formados a partir dos precursores I apresentaram grãos e agregados com dimensões de 45-100 nm. Enquanto os formados pelos precursores II e III apresentaram densidade muitíssimo elevada, não sendo possível a determinação do tamanho dos grãos. Os resultados de microscopia eletrônica de transmissão revelaram que a fase perovskita foi formada com pequena camada da fase pirocloro ao redor de seus grãos.

As medidas das propriedades elétricas revelaram que os filmes obtidos a partir dos precursores I apresentaram permissividade menor quando comparados aos obtidos pelos precursores II e III. Tal fato foi atribuído à densidade menor dos filmes obtidos pelos precursores I. As propriedades ferroelétricas não foram influenciadas pelos diferentes tipos de precursores ${ }^{38}$.

Merece destaque, não enquanto contraposição, mas, sim, enquanto complementaridade, o trabalho de Li e col. ${ }^{39}$. Estes autores fabricaram um dispositivo contendo um filme fino de $\mathrm{BaTiO}_{3}$ (BTO), obtido por sol-gel sobre um eletrodo de $\mathrm{LaNiO}_{3}$ (LNO), sendo este último obtido por $M O D$ sobre substrato de $\mathrm{LaAlO}_{3}$ (LAO). Os filmes de BTO apresentam potencialidade de aplicação em memórias dinâmicas de acesso aleatório (DRAM), dispositivos optoeletrônicos, moduladores e capacitores de filmes finos. A fabricação de eletrodos para capacitores de filmes ferroelétricos tem grande importância em memórias ferroelétricas e microsensores. Recentemente, filmes de óxidos metálicos têm substituído a platina como eletrodos. O óxido $\mathrm{LaNiO}_{3}$ (LNO) apresenta-se como forte candidato a ser utilizado como eletrodo, devido sua elevada condutividade.

Os filmes de BTO, preparados por sol-gel e depositados sobre o LNO (preparado por $M O D$ ), cresceram de forma orientada. Os resultados de espectroscopia Raman e de microscopia eletrônica de varredura mostraram que as multicamadas de filmes BTO/LNO/ substrato apresentaram alta cristalinidade e surperfície lisa. No que diz respeito às medidas elétricas, estas revelaram não só boa histerese ferroelétrica como, também, boas propriedades isolantes. Comparando-se as propriedades dielétricas do dispositivo BTO/LNO/ substrato com aquelas de um filme de BTO, depositado sobre um eletrodo inoxidável, constataram-se que a performance do BTO, utilizando o LNO como eletrodo de fundo, foi significativamente melhor. Atribuíram-se tal resultado a uma maior uniformidade da estrutura obtida através da combinação dos processos $M O D$ e sol-gel ${ }^{40}$.

\section{CRESCIMENTO, APLICAÇÕES E PERSPECTIVAS DA $M O D$}

Na Figura 4, está representada a distribuição (em porcentagen) de publicações referentes aos materiais com propriedades ferroelétricas, supercondutoras e outros, preparados por MOD. A terceira coluna, indicativa de materiais com outras propriedades, diz respeito aos diversos materiais que apresentam propriedades piezoeléctricas, magnéticas, eletro-ópticas e de óptica não-linear.

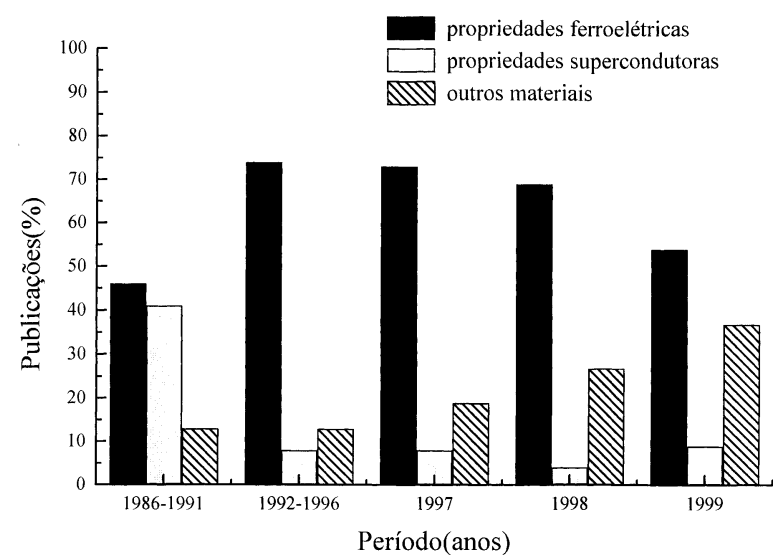

Figura 4. Tipos de materiais (propriedades), reportados de 1986-1999, preparados pelo processo MOD. 
O aumento na porcentagem de publicações envolvendo materiais com propriedades ferroelétricas é um indicativo de que o processo $M O D$ permite a obtenção de compostos com propriedades elétricas iguais, ou melhores, que aqueles preparados por outras técnicas, tais como sol-gel, $C V D, M O C V D$, etc.

Alguns dos materiais ferroelétricos mais investigados, preparados pelo processo $M O D$, são: $\mathrm{Pb}\left(\mathrm{Zr}_{1-\mathrm{x}} \mathrm{Ti}_{\mathrm{x}}\right) \mathrm{O}_{3}(\mathrm{PZT})^{11,41-48}, \mathrm{~Pb}_{1-\mathrm{x}} \mathrm{La}_{\mathrm{x}}\left(\mathrm{Zr}_{1}\right.$ $\left.\mathrm{Ti}_{\mathrm{y}}\right) \mathrm{O}_{3}(\mathrm{PLZT})^{49}, \mathrm{SrBi}_{2} \mathrm{Ta}_{2} \mathrm{O}_{9}{ }^{37,50-52}, \mathrm{~Pb}\left(\mathrm{Zn}_{1-\mathrm{x}} \mathrm{Nb}_{\mathrm{x}}\right) \mathrm{O}_{3}(\mathrm{PZN})^{53}$ $\mathrm{BaTiO}_{3}^{54-56}, \mathrm{Ba}_{1-\mathrm{x}} \mathrm{Sr}_{\mathrm{x}} \mathrm{TiO}_{3}\left(\mathrm{BST}^{57}, \mathrm{PbTiO}_{3}{ }^{11,56}, \mathrm{Bi}_{4} \mathrm{Ti}_{3} \mathrm{O}_{12}^{58}\right.$. Os mesmos apresentam grande potencialidade para aplicação em diversos tipos de dispositivos, como memórias não-voláteis (NV-RAMs), memórias dinâmicas de acesso aleatório (DRAMs), capacitores, sensores piro-ópticos e monitores eletro-ópticos, entre outros ${ }^{59}$.

A $M O D$ tem sido aplicada também à preparação de óxidos condutores transparentes, do tipo $\operatorname{In}_{2} \mathrm{O}_{3}{ }^{60}, \mathrm{In}_{2-\mathrm{x}} \mathrm{SnO}_{3}(I T O)^{28,61,62}$ e $\mathrm{SnO}_{2}$ dopado com flúor e antimônio ${ }^{63,64}$ e a supercondutores do tipo $\mathrm{YBa}_{2} \mathrm{Cu}_{3} \mathrm{O}_{7-\mathrm{x}}{ }^{65-68}$ e $\mathrm{Bi}(\mathrm{Pb})-\mathrm{Ca}-\mathrm{Sr}-\mathrm{CuO}^{69,70}$. Outros compostos preparados foram $\mathrm{ZnO}^{71}, \mathrm{LaNiO}_{3}{ }^{26}, \mathrm{LiNbO}_{3}{ }^{27,72}, \alpha-\mathrm{Fe}_{2} \mathrm{O}_{3}{ }^{73}$.

Tem-se notado um aumento recente do número de trabalhos reportados na literatura concernentes aos compostos de $\mathrm{SrBi}_{2} \mathrm{Ta}_{2} \mathrm{O}_{9}$ (SBT). Tais compostos apresentam propriedades ferroelétricas e são candidatos promissores para a produção de memórias não voláteis (NV-RAMs). Dentre as famílias de materiais ferroelétricos, os filmes de $\mathrm{Pb}(\mathrm{Zr}, \mathrm{Ti})_{3}$ (PZT) são os mais investigados, devido à sua polarização remanescente (Pr), campo coercitivo moderadamente pequeno (Ec) e alta temperatura de Curie. Todavia, os capacitores ferroelétricos, juntamente com eletrodos de Pt, sofrem fadiga e apresentam um declínio da polarização remanescente, após cerca de $10^{8}$ ciclos. Outro fator negativo está relacionado à toxidade do $\mathrm{Pb}$, o que impede que o material em questão seja produzido em larga escala.

Os filmes de SBT, preparados pela $M O D$, apresentaram boa qualidade estrutural, morfológica e suas propriedades ferroelétricas foram satisfatórias ${ }^{50}$. A fase perovskita do SBT formou-se a $650^{\circ} \mathrm{C}$, com uma hora de tratamento térmico e com pequena quantidade da fase pirocloro (fase deletéria para as propriedades ferroelétricas). As imagens da superfície dos filmes de SBT revelaram, em função da temperatura de cristalização, morfologia com grãos na forma de bastonetes, com diâmetro variando entre 100 e $250 \mathrm{~nm}$. As propriedades de fadiga dos filmes de SBT foram avaliadas após $10^{10}$ ciclos de voltagem, tendo os resultados mostrado que os filmes submetidos a ciclos com voltagem menor (3V) sofreram uma degradação na polarização. Entretanto, quando submetidos a voltagem maior, a polarização mostrou-se reversível.

Filmes finos de óxido de índio dopado com estanho (ITO) foram preparados por $M O D$, com composição nominal $\mathrm{In}_{1,91} \mathrm{Sn}_{0,09} \mathrm{O}_{3}^{28}$. Tal composto é muito utilizado como eletrodo transparente em vários dispositivos ópto-eletrônicos, por apresentar, simultaneamente, condutividade e transparência elevadas. Os filmes de ITO, produzidos por $M O D$, mostraram propriedades elétricas comparáveis àquelas dos filmes produzidos por outras técnicas, contudo, com propriedades ópticas superiores. Os filmes eram uniformes e com rugosidade equivalente à do substrato $\left(\mathrm{SiO}_{2}\right.$ amorfo $)$, quando aquecidos diretamente a $550{ }^{\circ} \mathrm{C}$, antes da cristalização.

$\mathrm{O}$ vanadato de bismuto, $\mathrm{BiVO}_{4}$, material termocrômico - o mais provável substituto para pigmentos amarelos, utilizados atualmente -, por ser livre de complicações ecotoxicológicas, foi obtido, pela primeira vez, no Laboratório de Química do Estado Sólido (LQES), do Instituto de Química da UNICAMP, na forma de filmes finos, utilizando-se a técnica de $M O D^{22}$. A aplicação da técnica permitiu, também, o controle do tamanho dos cristalitos, quando da preparação do $\mathrm{BiVO}_{4}$ na forma de sólido policristalino, em temperaturas inferiores àquelas usualmente empregadas para a obtenção deste sólido pelos métodos de reação sólido-sólido e sol-gel não-hidrolítico ${ }^{29,74}$. A aplicação da $M O D$ em materiais deste tipo permite, com modificações mínimas nas condições experimentais, estender o método a outros materiais à base de bismuto-vanádio, com diferentes razões estequiométricas.

Outros compostos obtidos no LQES, pelo processo $M O D$, foram o $\mathrm{Cd}_{2} \mathrm{SnO}_{4}{ }^{31,75}, \mathrm{Cd}_{2} \mathrm{Sb}_{2} \mathrm{O}_{7}$ e $\mathrm{Cd}_{2} \mathrm{Nb}_{2} \mathrm{O}_{7}$. Tais compostos pertencem a uma classe de materiais que têm como características principais banda proibida larga (wide band gap), o que lhes confere transmissão óptica elevada na região do visível.

A obtenção de Sistemas Químicos Integrados (SQIs), é outro exemplo interessante da aplicação da técnica $M O D$. Os sistemas em questão podem ser definidos como heterogêneos, contendo multifases desenhadas e arranjadas de forma específica. Os diferentes componentes estão organizados de maneira a apresentar efeitos cooperativos (sinergismo), sendo suas propriedades determinadas pelas interações entre os diferentes componentes constituintes, de modo que o sistema, como um todo, possa apresentar uma estrutura específica e/ou executar uma determinada função. Filmes de $\mathrm{CeO}_{2}$, preparados por $M O D$, vêm sendo utilizados em Sistemas Químicos Integrados ${ }^{23,76,77}$. $\mathrm{O} \mathrm{CeO}$ tem recebido grande atenção, por suas propriedades isolantes. Fukuda e col. depositaram filmes de $\mathrm{CeO}_{2}$, sobre substrato de $\mathrm{Si}(100)$, pela $M O D$. Estes foram tratados termicamente, em atmosfera de $\mathrm{O}_{2}$, em temperaturas entre $600{ }^{\circ} \mathrm{Ce} 800{ }^{\circ} \mathrm{C}$. A espessura do filme de $\mathrm{CeO}_{2}$ foi de $31,8 \mathrm{~nm}$ e, do filme interfacial de $\mathrm{SiO}_{2}$, de 5,2 nm. A espessura do filme de $\mathrm{SiO}_{2}$ mostrou-se proporcional à temperatura de cristalização em atmosfera de oxigênio. Tal comportamento foi atribuído ao fato de que, durante a cristalização, os átomos de oxigênio difundem-se pela camada do filme de $\mathrm{CeO}_{2}$, para o substrato de $\mathrm{Si}$, produzindo a estrutura $\mathrm{CeO}_{2} / \mathrm{SiO}_{2} / \mathrm{Si}$. As medidas de capacitância-voltagem para estes filmes mostraram boas propriedades dielétricas, sendo o valor da constante dielétrica 15 , ou seja, três vezes maior do que para o $\mathrm{SiO}_{2}$.

Galembeck e Alves apresentaram, também, empregando MOD, interessante exemplo de fabricação de um SQI, polimerizando pirrol sobre a superfície de filmes de $\mathrm{CeO}_{2}{ }^{77}$. Os filmes de $\mathrm{CeO}_{2}$ foram depositados sobre substrato de vidro e apresentaram-se com uma morfologia semicontínua, dependente das variáveis de preparação. Os resultados de espectroscopia Raman com resolução espacial mostraram partículas de óxido recobertas por uma camada contínua de polímero. A proposição do mecanismo para a formação do polímero sobre a superfície do óxido considerou a reação redox entre o pirrol e os íons $\mathrm{Ce}^{4+}$, com formação de íons $\mathrm{Ce}^{3+}$. As medidas de condutividade dos filmes de $\mathrm{CeO}_{2} /$ polipirrol/substrato variaram de 1,9 a $3,0 \times 10^{-4} \mathrm{~S} / \mathrm{cm}^{2}$, enquanto obteve-se o valor de $1,21 \times 10^{-12} \mathrm{~S} /$ $\mathrm{cm}^{2}$, para o substrato recoberto apenas por $\mathrm{CeO}_{2}$. Este sistema apresenta propriedades fotoeletroquímicas, antevendo-se a possibilidade de sua aplicação em catálise ambiental.

A $M O D$ revela-se, ainda, como uma técnica extremamente promissora, devido à sua facilidade de adaptação a vários tipos de processos de fabricação de dispositivos: patterning, por aplicação de feixe de íons ${ }^{78,79}$; litografia com feixe de laser ${ }^{80}$; fotolitografia ${ }^{81}$, entre outras.

No caso do patterning, tem-se como hipótese que o impacto dos íons ou elétrons induz a quebra nas ligações dos metalorgânicos, tornando-os insolúveis no solvente usado para sua deposição, e que o patterning com o feixe de laser decompõe o precursor em regiões localizadas. O mecanismo exato de decomposição para esses processos não esta ainda totalmente elucidado.

Alguns autores têm mostrado a possibilidade de obtenção de fibras de materiais ferroelétricos e supercondutores a partir de precursores do tipo carboxilatos metálicos, utilizados juntamente com alcóxidos $^{82-84}$. 
A Figura 5 apresenta o resultado de levantamento recente sobre trabalhos que utilizaram a técnica de $M O D$ na preparação de filmes finos.

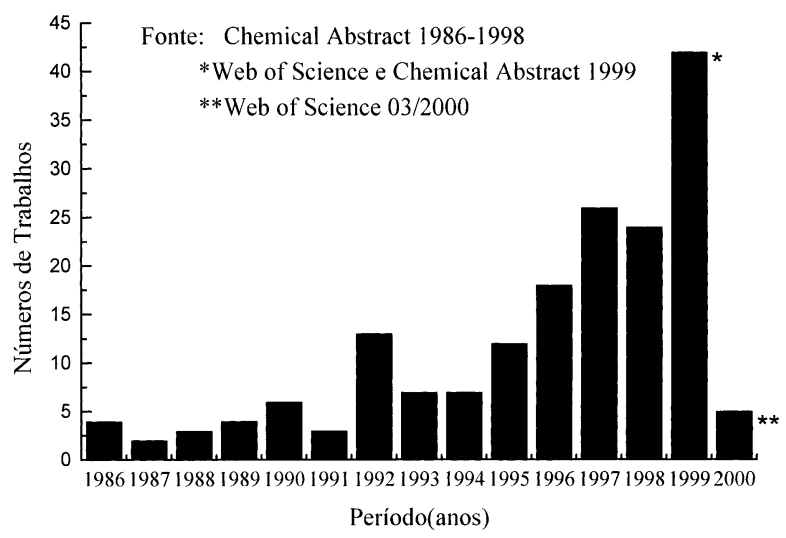

Figura 5. Número de trabalhos envolvendo a preparação de filmes finos por MOD, reportados de 1986 a março de 2000.

Nota-se um aumento significativo de trabalhos publicados, especialmente a partir de 1995. Entre 1986 e 1997, o número de trabalhos aumentou 6,5 vezes. Quando comparados com o processo solgel, os números revelam que este é ainda bem mais utilizado na preparação de filmes finos de óxidos.

Ressalte-se que, nesta revisão, foram apresentados, exemplos nos quais a aplicação da $M O D$ levou a melhores resultados quer em termos de robustez e homogeneidade dos filmes, quer em termos de propriedades. Certamente isso não será verdadeiro para todo e qualquer sistema que se pretenda investigar e fabricar filmes finos. Acreditamos que, devido às várias vantagens oferecidas pela $M O D$, principalmente no que se refere ao controle maior das propriedades estruturais e morfológicas (o que permite que as propriedades de interesse sejam melhor moduladas), o número de trabalhos e aplicações tenderá a crescer.

A evolução da aplicação da técnica $M O D$ terá cada vez mais êxito, na medida em que materiais possam ser incrementados pela criação de rotas de preparação simples e economicamente viáveis. Poderá a mesma vir a se tornar uma metodologia alternativa para os casos em que as técnicas concorrentes mostraram-se ineficientes, desde que, conjuntamente, tenhamos um importante desenvolvimento de novos e adequados precursores.

\section{CONCLUSÕES}

A $M O D$ tem sido utilizada com resultados satisfatórios para a obtenção de diversos tipos de materiais, na forma de filmes finos, com estequiometria controlada. Tais filmes podem ser depositados por diferentes técnicas (dip coating, spin coating, etc.). Modulando-se o tratamento térmico, tipo de precursor e outras variáveis de processo, pode-se chegar à estrutura desejada. A evolução da morfologia dos filmes está relacionada com vários fatores, dentre eles, a cinética de decomposição dos precursores. Desta forma, o estudo dos processos de decomposição por técnicas de análises térmicas são fundamentais na obtenção dos parâmetros a serem utilizados na preparação dos filmes.

Nos últimos anos, o aumento no número de publicações, mostra que este processo vem ganhando cada vez mais espaço e importância, principalmente na preparação de materiais ferroelétricos.

Os dois principais fatores que contribuem para este fato são: i) estabilidade dos precursores às condições ambientes. Não se faz necessária a manipulação em atmosfera inerte, nem a utilização de sistemas à vácuo, no manuseio e deposição dos precursores; ii) não é necessário controle rigoroso das condições de reação, permitindo a obtenção de sistemas multicomponentes. O primeiro item se constitui na principal vantagem da $M O D$ sobre a $C V D$, sendo que esta última apresenta dificuldades quando se tem diferentes volatilidades dos distintos precursores. Na $M O D$, o controle reacional, via de regra, não constitui empecilho, como no caso do processo sol-gel, no qual a ausência de controle reacional pode gerar compostos cujas estruturas e propriedades não são reprodutíveis. Além disso, existem, ainda, muitos sistemas de interesse científico e tecnológico, aos quais a técnica $M O D$ não foi cogitada abrindo-se, assim, vasto campo para a pesquisa básica e aplicada.

Neste sentido, papel fundamental cabe ao químico inorgânico sintético: exercitar todo o seu conhecimento e talento no sentido de prover precursores de elevado grau de pureza, solúveis em solventes usuais, que permitam a obtenção de materiais monofásicos utilizando temperaturas menores que aquelas utilizadas quando das reações sólido-sólido.

\section{AGRADECIMENTOS}

Os autores agradecem ao PRONEX (MCT) pelo financiamento e à FAPESP pela concessão de Bolsa de Doutorado (C.M.R., 98/ 07902-8). Agradece ainda, ao Prof. Dr. Ernesto C. Pereira, DQUFSCar, pelas facilidades na utilização do equipamento TGA-EM.

\section{REFERÊNCIAS}

1. De Oliveira S.C.; Torresi R.M.; De Torresi S.I.C.; Quim. Nova 2000, 23, 79.

2. Olivi P.; Pereira E.C.; Longo E.; Varella J.A.; Bulhões L.O.S.; J. Electrochem. Soc. 1993, 140, L81.

3. Rudiono; Kaneko, F.; Takeuchi, M.; Appl. Surf. Sci. 1999, 142, 598.

4. Nogueira, A.F.; De Paoli, M.A.; Sol. Energ. Mat. Sol. Cells 2000, 61, 135.

5. Zhang, H.X.; Kam, C.H.; Zhou, Y.; Han, X.Q.; Xiang, Q.; Buddhudu, S.; Lam, Y.L.; Chan, Y.C.; J. Alloy Compd. 2000, 308, 134.

6. Safonova, O.V.; Rumyantseva, M.N.; Kozlov, R.I.; Labeau, M.; Delabouglise, G.; Ryabova, L.I.; Gaskov, A.M.; Mat. Sci. Eng. B 2000, 77, 159.

7. Ehrlich, G.M.; Schleich, D.M.; Sensors and Actuat. A-Phys., 1995, $51,17$.

8. Nadenau, V.; Rau, U.; Jasenek, A.; Schock, H.W.; J. Appl. Phys. 2000, $87,584$.

9. Zhu, B.; Solid State Ionics 1999, 119, 305.

10. Schmool, D.S.; Keller, N.; Guyot, M.; Krishnan, R.; Tessier, M.; J. Appl. Phys. 1999, 86, 5712.

11. Vest, R. W.; Ferroelectrics 1990, 102, 53.

12. Minassian-Saraga, L. T; Pure Appl. Chem. 1994, 66, 1667.

13. Maissel, L. Application of Sputtering to Deposition of Films, Handbook of Thin Film Technology; Maissel L.; Glang R. Eds.; McGraw Hill Book Co; New York, 1970; p. 4.

14. Pulker, H. K. Coatings on Glass; Elsevier Sci. Pub.; Amsterdam, 1984, p. 92.

15. Kuo, C.Y. Solid State Technol. 1974, 17, 49.

16. Krupanidhi, S. B.; Peng, C. J.; Thin Solid Films 1997, 305, 144.

17. Zhang, Z. G.; Wang, Y. N.; Zhu, J. S.; Yan, F.; Lu, X. M.; Shen, H. M.; Liu, J. S.; Appl. Phys. Lett. 1998, 73, 3674.

18. Hu, G. D.; Wilson, I. H.; Xu, J. B.; Cheung, W. Y.; Wong, S. P.; Wong, H. K.; Appl. Phys. Lett. 1999, 74, 1221.

19. Zhang, Z. G.; Liu, J. S.; Wang, Y. N.; Zhu, J. S.; Yan, F.; Chen, X. B.; Shen, H. M.; Appl. Phys. Lett. 1998, 73, 788.

20. Vest, G. M.; Singaram, S.; Mat. Res. Soc. Symp. Proc.,1986, 60, 35

21. Manifacier, J. C.; Fillard, J. F.; Bird, J. M.; Thin Solid Films 1981, 77, 67.

22. Galembeck, A.; Alves, O. L.; Thin Solid Films 2000, 365, 90.

23. Galembeck, A.; Alves, O. L.; Synthetic Metals 1999, 102, 1238.

24. Silverstain, R. M.; Bassler, G. C.; Morril, T. C. Spectrometric Identification of Organic Compounds; $5^{\mathrm{a}}$ ed.; Jonh Wiley \& Sons; New York, 1991, p.44.

25. Brinker, C. J.; Frye, G. C.; Hurd, A. J.; Ashley, C. S.; Thin Solid Films 1991, 201, 97

26. Li, A. D.; Ge, C. Z.; Wu, D.; Lü, P.; Zuo, Y. Q.; Yang, S. Z.; Ming, N. B.; Thin Solid Films 1997, 298, 165.

27. Braunstein, G.; Paz-Pujalt, G. R.; Blanton, T. N.; Thin Solid Films 1995, $264,4$. 
28. Xu, J. J.; Shaikh, S. A.; Vest, R. W.; Thin Solid Films 1988, 161, 273.

29. Galembeck, A.; Tese de Doutorado; Instituto de Química, UNICAMP; Campinas, 1998.

30. Barros Neto, B.; Scarmínio, I.S.; Bruns, R.E. Planejamento e Otimização de Experimentos; Editora da Unicamp; Campinas, 1995; p. 61-131.

31. Ronconi, C. M.; Alves, O. L.; Resumos, $23^{a}$ Reunião Anual da Sociedade Brasileira de Química, Poços de Caldas, MG, 2000.

32. Barreca, D.; Depero, L. E.; Noto, V. D.; Rizzi, G. A.; Sangaletti, L.; Tondello, E.; Chem. Mater. 1999, 11, 255.

33. Zarbin, A. J. G.; Alves, O. L.; Vargas, M. D.; Quim. Nova 1995, 18, 274.

34. MOVPE'96, J. Cryst. Growth 1997, 170.

35. Paz-Pujalt, G. R.; Nie, W.; Lurin, C.; Mat. Res. Soc. Symp. Proc. 1992, 271, 193.

36. Klee, M.; Mackens, U.; Integrated Ferroelectrics 1996, 12, 11.

37. Hu, Y.; J. Mat. Sci. 1996, 31, 4255.

38. Klee, M.; Eusemann, R.; Waser, R.; Brand, W.; Van Hal, H.; J. Appl. Phys. 1992, 72, 1566

39. Li, A. D.; Ge, C. Z.; Lü, P.; Wu, D.; Xiong, S.; Ming, N. B.; Appl. Phys. Lett. 1997, 70, 1616.

40. Wu, D.; Li, A. D.; Liu, Z.; Ling, H.; Ge, C .Z.; Liu, X.; Wang, H.; Wang, M.; Lü, P.; Ming, N. B.; Thin Solid Films 1998, 336, 172.

41. Zhu, W.; Liu, Z. Q.; Tse, M. S.; Tan, H. S.; J. Mat. Sci.: Materials in Electronics 1995, 6, 369.

42. Zhu, W. R.; Vest, W.; Tse, M. S.; Rao, M. K.;. Liu, Z. Q; J. Mat. Sci.: Materials in Electronics 1994, 5, 173.

43. Nieto, E.; Fernandez, J. F.; Moure, C.; Duran, P.; J. Mat. Sci. 1995, 30 6243.

44. Klee, M.; Larsen, P. K.; Ferroelectrics 1992, 133, 91.

45. Zhu, W.; Vest, R. W.; Tse, M.S.; Ferroelectrics 1994, 157, 393.

46. Fukushima, J.; Kodaira, K.; Matsushita, T.; J. Mat. Sci. 1984, 19, 595.

47. Vest, R. W.; Xu, J.; Ferroelectrics 1989, 93, 21.

48. Chen, S-Y.; Chen, I-W.; Jpn. J. Appl. Phys. 1997, 36, 4451.

49. Hayashi, T.; Takahashi, H.; Hara, T.; Jpn. J. Appl. Phys. 1996, 35, 4952.

50. Zhang, Z. G.; Liu, J. S.; Wang, Y. N.; Zhu, J. L.; Su, D.; Shen, H. M.; J. Appl. Phys. 1999, 85, 1746.

51. Noguchi, T.; Takashi, H.; Miyasaka, Y.; Jpn. J. Appl. Phys. 1996, 35, 4900

52. Ogata, N.; Nagata, M.; Ishihara, K.; Urashima, H.; Okutoh, A.; Yamazaki, S.; Mitarai, S.; Kudo, J.; Jpn. J. Appl. Phys. 1998, 37, 3481.

53. Hanrahan, J. R.; Sanchez, E.; Santiago, J. J.; Berry, D. H.; Jiang, Q.; Thin Solid Films 1991, 202, 235.

54. Shaikh, A. S.; Vest, R. W.; J. Am. Ceram. Soc. 1986, 69, 689.

55. Shaikh, A. S.; Vest, G. M.; J. Am. Ceram. Soc. 1986, 69, 682.

56. Catalan, A. B.; Mantese, J. V.; Micheli, A. L.; Schubring N. W.; Poisson, R. J.; J. Appl. Phys. 1994, 76, 2541.

57. Mohamed, M. S.; Auner, G. W.; Naik, R.; Mantese, J. V.; Schubring, N. W.; Micheli, A. L.; Catalan, A. B.; J. Appl. Phys. 1998, 84, 3322.
58. Okamura, S.; Yagi, Y.; Mori, K.; Fujihashi, G.; Ando, S.; Tsukamoto, T.; Jpn. J. Appl. Phys. 1997, 36, 5889.

59. Haertling, G. H.; J. Vac. Sci. Technol. A 1991, 9, 414.

60. Sawada, Y.; Omika, K.; Ito, Y.; Muta, F.; Momota, M.; J. Thermal Anal. 1993, 40, 1145.

61. Furusaki, T.; Kodaira, K.; Yamamoto, M.; Shimada, S.; Matsushita, T.; Mat. Res. Bull. 1986, 21, 803.

62. Gallagher, D.; Scanlan, F.; Houriet, R.; Mathieu, H. J.; Ring, T. A.; J. Mat. Res. 1993, 8, 3135 .

63. Maruyama, T.; Kitamura, K.; Jpn. J. Appl. Phys. 1989, 28, L312.

64. Tsunashima, A.; Yoshimizu, H.; Kodaira, K.; Shimada, S.; Matsushita, T.; J. Mat. Sci. 1986, 21, 2734.

65. Hung, L. S.; Lee, S. T; Braunstaein, G. H.; Agostinelle, J. A.; J. Appl. Phys. 1989, 66, 463.

66. Nasu, H.; Makita, S.; Imura, T.; Osaka, Y.; J. Mat. Sci. Lett. 1988, 7, 858.

67. Nasu, H.; Makita, S.; Kato, T.; Ibara, Y.; Imura, T.; Osaka, Y.; Chem. Lett. 1987, 122403.

68. Fang, S. C.; Huang, C. H.; Chen, I. C.; Liaw, C. F.; Hurng, W. M.; J. Mat. Sci. 1994, 29, 99.

69. Golden, S. J.; Bloomer, T. E.; Lange, F. F.; Segadaes, A. M.; Vaidya, K. J.; Cheetham, A. K.; J. Am. Ceram. Soc. 1991, 74, 123.

70. Klee, M.; Marbach, G.; Stotz, S.; de Vries, J. W. C.; J. Less Common Metals 1989, 151, 393.

71. Jean, J. H.; J. Mat. Sci. Lett. 1990, 9, 127.

72. Wu, R. C. R.; Vest, R. W.; Ceram. Trans. 1990, 11, 319.

73. Xue, S.; Ousi-Benomar, W.; Lessard, R. A.; Thin Solid Films 1994, 250, 194.

74. Medeiros, M. E.; Tese de Doutorado; Instituto de Química, UNICAMP, Campinas, 1995.

75. Ronconi, C. M.; Alves, O. L.; Resumos, $22^{a}$ Reunião Anual da Sociedade Brasileira de Química, Poços de Caldas, MG, 1999.

76. Fukuda, H.; Miura, M.; Sakuma, S.; Nomura, S.; Jpn. J. Appl. Phys. 1998, 37, 4158 .

77. Galembeck, A.; Alves, O. L. Synthetic Metals 1997, 84, 151.

78. Mantese, J. V.; Catalan, A. B.; Hamdi, A. H.; Micheli, A. L.; Appl. Phys. Lett. 1988, 52, 1741 .

79. Hung, L. S.; Zheng, L. R.; Appl. Phys. Lett. 1992, 60, 2210.

80. Norton, J. L.; Mansour, S. A.; Lield, G. L.; Bemet, A. L. J.; Slamovich, E. B.; Venkatraman, C.; Mat. Res. Soc. Symp. Proc. 1995, 380, 99.

81. Xue, S.; Ousi-Benomar, W.; Lessard, R. A.; Opt. Eng. 1994, 33, 2442.

82. Chen, K. C.; Zheng, H.; Mackenzie, J. D.; US Pat., 5,072,035.

83. Zhang, Z. F.; Kennish, R. A.; Blohowiak, K. A. Y.; Hoppe, M. L.; Laine, R. M.; J. Mat. Res. 1993, 8, 1777.

84. Chen, K. C.; Mazdiyashni, K. S.; Mat. Res. Soc. Symp. Proc. 1990, 169, 1213. 